
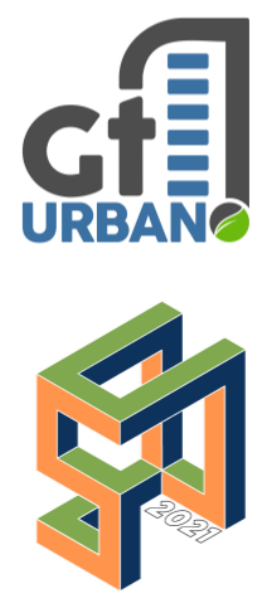

\section{SInGEURB}

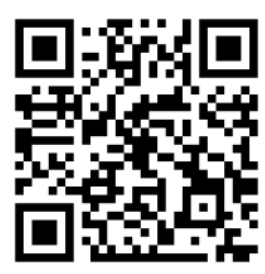

Como citar:

ALMEIDA, Vitor

Laytynher Santos de;

INGUAGGIATO,

Felipe Facci;

STANGANINI, Fábio

Noel. A utilização de

Veículos Aéreos Não

Tripulados como

ferramenta de

avaliação da

degradação de rios

urbanos: $\mathrm{O}$ caso do

Córrego do Gregório,

São Carlos-SP. In: III

SIMPÓSIO

NACIONAL DE

GESTÃO E

ENGENHARIA

URBANA:

SINGEURB, 2021,

Maceió. Anais... Porto

Alegre: ANTAC, 2021.

p. 538-546.

Disponível em:

https://eventos.antac.

org.br/index.php/sin

geurb/issue/view/14

\title{
A Utilização de Veículos Aéreos Não Tripulados como Ferramenta de Avaliação da Degradação de Rios Urbanos: $O$ caso do Córrego do Gregório, São Carlos-SP
}

\author{
The use of Remotely Piloted Aircrafts as a tool to \\ assess urban rivers degradation: The case of \\ Gregório's Creek, São Carlos-SP
}

Vitor Laytynher Santos De Almeida, UFSCAR, vlaytynher@gmail.com

Felipe Facci Inguaggiato, UFSCAR, fp.facci@hotmail.com

Fábio Noel Stanganini, UFSCAR, fstanganini@ufscar.br

\section{RESUMO}

Um típico problema encontrado nas cidades brasileiras é a forma como os rios são integrados ao espaço urbano. Isto ocorre normalmente pela completa descaracterização do ecossistema fluvial através da remoção de mata ciliar, alteração das margens e lançamento de resíduos antrópicos. Essa pesquisa pretende através de experimentação prática verificar a contribuição que veículos aéreos não-tripulados (VANT's) podem fornecer a fim de se verificar o nível de degradação imposto a um rio urbano. Foi realizado imageamento através de VANT num trecho do córrego do Gregório e entorno, na cidade de São Carlos-SP, de forma que os dados obtidos seguiram para tratamento num sistema de informação geográfica de acordo com indicadores das condições de degradação de cursos d'água. Os indicadores adotados foram presença de mata ciliar, ocorrência de erosão, modificações no curso d'água, poluição, e a presença de edificações em área protegida. Através das imagens coletadas pelo VANT, foi possível demarcar áreas de vegetação remanescente e de edificações invasoras sem dificuldades, bem como identificar trechos do rio que sofreram intervenção. No entanto, características pontuais como processos erosivos ou lançamentos de efluentes se mostraram incertos. Conclui-se que o emprego de VANT constitui uma nova tecnologia para ajudar os estudos ambientais no meio urbano.

Palavras-chave: VANT, Rio Urbano, Planejamento Territorial.

\begin{abstract}
A typical problem found in Brazilian cities is the way rivers are integrated into the urban environment. It normally occurs through complete de-characterization of the river ecosystem by removing riparian vegetation, changing riverbanks, or disposing waste from human activities. This paper uses practical experimentation to verify the contribution that remotely piloted aircrafts (RPA) can provide in order to assess the degradation level of an urban river. It was performed a imaging along a segment of the Gregório's creek and its surroundings in the city of São Carlos-SP with the aid of a RPA, and the collected data was then processed in
\end{abstract}


a geographical information system according to some indicators of the river degradation. These indicators were the presence of riparian vegetation, the occurrence of erosion, riverbed and banks modification, pollution, and presence of buildings in riparian buffer strip. Using the collected images, it was possible to draw the current vegetation and the invasive buildings areas, and to identify segments in which the riverbanks were modified. However, spot located features, such as erosion process or wastewater discharge, revealed to be of uncertain. In conclusion, RPA represents a new technology to help environmental studies in urban areas.

Keywords: RPA, Urban River, Urban Planning.

\section{INTRODUÇÃO}

O adensamento populacional histórico, atrelado ao rápido processo de urbanização, levam a uma série de problemáticas, tanto de cunho socioeconômico, quanto ambiental, e cabe ao poder público solucioná-las (VILLAÇA, 2001). Todavia, essas questões não foram solucionadas - fruto da falta de políticas públicas preventivas (ROLNIK, 2015) - e principalmente fruto da lacuna relacionada à necessidade de maior detalhamento no tocante a análise de políticas públicas em escalas locais (BATISTA DE FRANÇA, 2017).

Questões como enchentes, poluição de corpos hídricos e supressão de áreas verdes são fundamentalmente o principal reflexo dessa má gestão do espaço urbano. Assim, a utilização de materiais cartográficos georreferenciados para controle de áreas de proteção permanente (APP) contribui significativamente para a gestão urbana.

Entretanto, técnicas e ferramentas já difundidas para levantamento aerofotogramétrico dessas áreas esbarram tanto nos seus elevados custos operacionais (GALLACHER, 2016) - dificultando o planejamento territorial por órgãos públicos - quanto na baixa resolução espacial e na falta da demanda de escalas condizentes com a análise local.

Ainda assim, observa-se que o uso de imagens com alta resolução espacial - com menor custo operacional - está cada vez mais difundido em questões urbanas. Isso ocorre, principalmente, através da utilização dos Veículos Aéreos Não Tripulados (VANT) (CURETON, 2020), responsáveis por novas funcionalidades e possibilidades de aplicação. Portanto, a utilização dos VANT's representa uma nova alternativa de levantamentos aerofotogramétricos que permitem maior detalhamento para gestão de rios urbanos e áreas de APP.

O presente trabalho tem como objetivo avaliar a aplicação dos produtos obtidos pelos VANT's no reconhecimento do impacto ambiental sofrido em um rio urbano localizado em São Carlos-SP. Com isso, pretende-se demonstrar seu potencial como ferramenta de auxílio ao planejamento urbano. 2

\section{REVISÃO BIBLIOGRÁFICA}

A interação cidade-corpo d'água é bastante influenciada pelo uso/função que a cidade atribui às margens de seus rios, lagos, etc. Essas margens podem ser usadas para atividades econômicas, como vias de transporte, e também para moradias, muitas vezes precárias e sujeitas a inundações. As margens dos rios urbanos podem ainda ser usadas para atividade físicas e lazer (COY, 2013).

Ao se ocupar essas áreas ribeirinhas, são realizadas obras de engenharia que visam imobilizar as margens dos corpos d'água, que apresentam como efeito colateral um considerável impacto visual e altos custos de 
manutenção. Essas consequências têm levado gestores urbanos a considerarem soluções que conciliem urbanização e preservação das características ambientais (COSTA, 2011).

Segundo Dalla Costa (2008), a degradação de um corpo d'água ocorre segundo determinados processos. O primeiro deles seria a retirada da mata ciliar, cuja supressão leva ao assoreamento, a processos erosivos e inundações de várzeas, além da diminuição de biodiversidade. O segundo processo seria exatamente a erosão das margens, que gera turbidez nas águas e contribui para morte de fauna e flora. Outro processo de degradação ocorre pelas modificações nos cursos d'água, como retificações de margem, construção de pontes, canalizações e tamponamentos. Tais intervenções destroem o ecossistema e alteram o comportamento hidrológico do corpo hídrico. O penúltimo processo de degradação seria o lançamento de resíduos sólidos e efluentes nos rios e lagos, provocando mau odor, desequilíbrio no ecossistema, e um impacto paisagístico bastante negativo. Por fim, há o processo de edificação nas margens de corpos d'água, aumentando a área impermeável, e por consequência o volume de água que chega nos córregos e lagos, contribuindo assim para inundações frequentes.

Essa mudança na forma de lidar com os corpos hídricos urbanos tem como primeiro passo a caracterização situacional dos mesmos, ou seja, é preciso descrever as condições de degradação em que se encontram. Tal tarefa encontra nas geotecnologias ferramentas bastante adequadas.

Em especial, o emprego de VANT's no sensoriamento remoto possibilita a obtenção de imageamento de alta precisão capaz de fornecer as características necessárias para o estudo dos corpos d'água urbanos.

\section{CARACTERIZAÇÃo DA ÁREA DE ESTUDOS}

A área de estudos situa-se no município de São Carlos, no estado de São Paulo. Conforme o Seade (2020), apresenta taxa de urbanização de $96 \%$ e uma densidade populacional de 195,15 habitantes por km². Quanto ao rio estudado, trata-se do córrego do Gregório, pertencente a bacia hidrográfica do rio Monjolinho. 
Figura 1. Localização da Área de Estudos

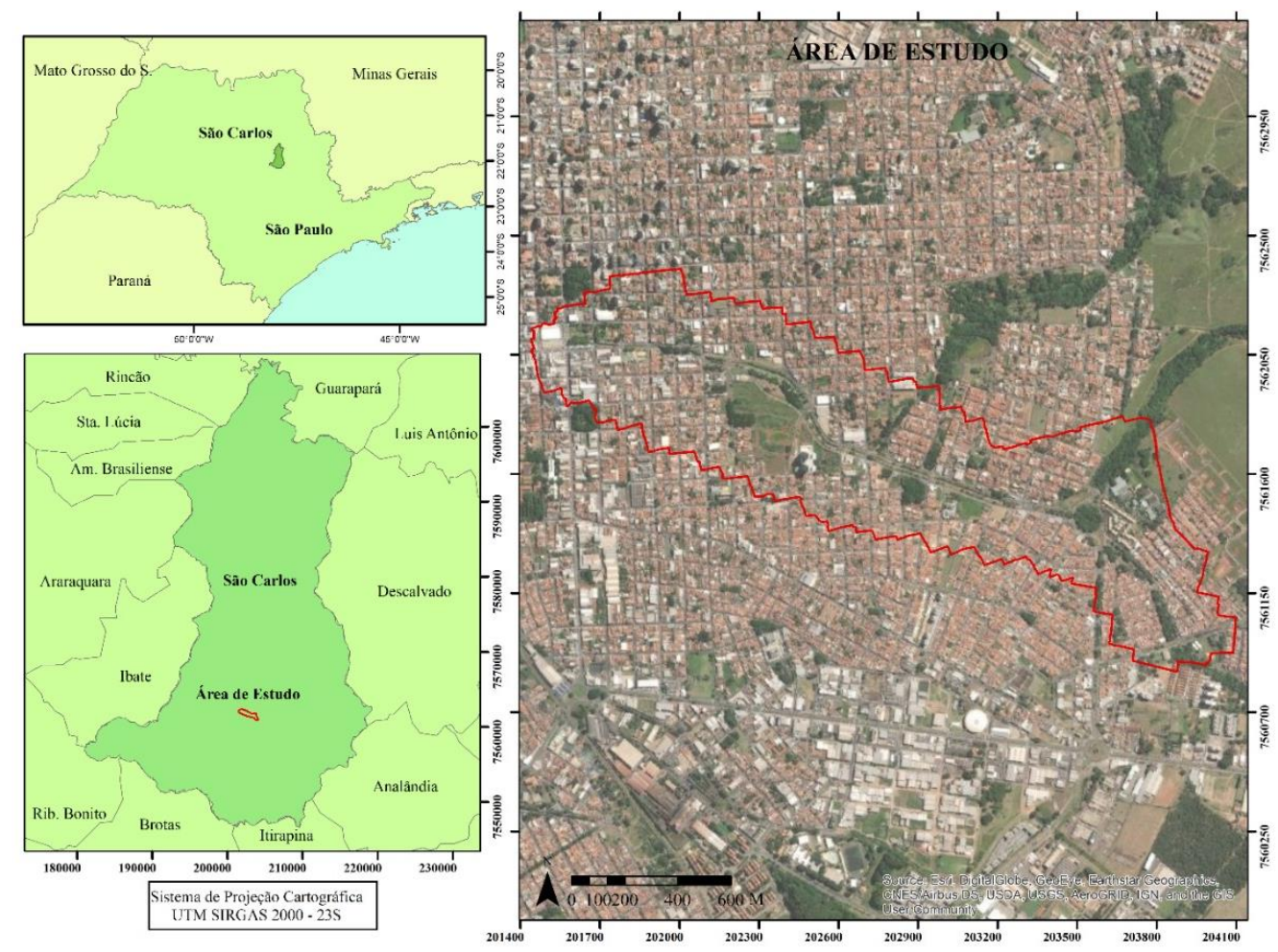

Fonte: Autores (2021)

\section{METODOLOGIA}

Primeiramente se promoveu a identificação da área de estudos, com sua escolha e delimitação. A Figura 2 ilustra o fluxograma relacionado aos procedimentos abordados ao longo do trabalho.

Figura 2. Fluxograma Metodológico

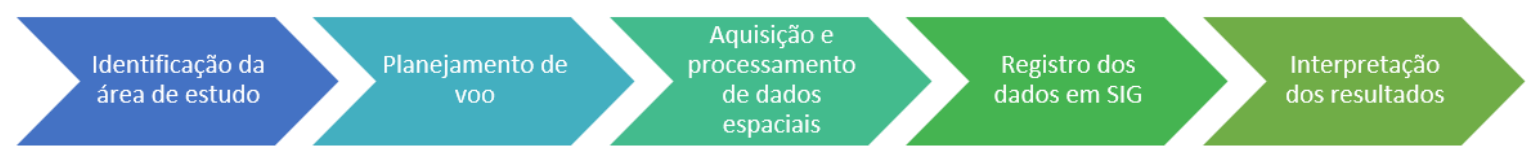

Fonte: Autores (2021).

A etapa posterior consistiu em estipular a rota, a altura e a sobreposição das imagens obtidas pelo VANT. Neste momento, foi utilizado o software "Map Pilot" a fim de configurar a altitude de 120 metros, com sobreposições de $80 \%$ longitudinal e $70 \%$ latitudinal. Estas questões são de suma importância para obtenção de um produto com melhor nível de detalhamento e resolução espacial.

A terceira etapa começa com a aquisição dos dados pela realização de 2 voos do VANT, com duração total de 20 minutos, percorrendo uma área de 115,7 hectares. Utilizou-se o VANT modelo DJI Phantom 4 PRO. Passou-se então para o processamento das imagens obtidas. O software "Agisoft Metashape" foi responsável por transformar as imagens captadas em ortofotos através da combinação de pontos semelhantes. 
Quadro 1 - Fatores utilizados para análise da degradação dos corpos d'água

\begin{tabular}{|c|c|c|}
\hline Indicador & Parâmetro & Análise \\
\hline Mata Ciliar & Remoção de vegetação & Percentual da APP com área verde remanescente \\
\hline $\begin{array}{l}\text { Erosão e } \\
\text { Assoreamento }\end{array}$ & Processo erosivo nas margens & $\begin{array}{l}\text { Quantidade de pontos de erosão nas margens e } \\
\text { efeitos na estabilidade }\end{array}$ \\
\hline \multirow{3}{*}{$\begin{array}{l}\text { Modificações no } \\
\text { curso d'água }\end{array}$} & Retificação da seção transversal & $\begin{array}{l}\text { Comprimento do trecho e áreas modificadas (leito e } \\
\text { margens) }\end{array}$ \\
\hline & Mudança de revestimento & $\begin{array}{l}\text { Comprimento do trecho e tipo de revestimento } \\
\text { adotado (liso ou rugoso) }\end{array}$ \\
\hline & Canalização ou tamponamento & Comprimento do trecho \\
\hline \multirow{2}{*}{ Poluição } & Lançamento de efluentes & $\begin{array}{l}\text { Quantidade de pontos de lançamento de efluente } \\
\text { no trecho }\end{array}$ \\
\hline & Acúmulo de resíduo sólido & $\begin{array}{l}\text { Quantidade de pontos de acúmulo de resíduo } \\
\text { sólido na área de APP }\end{array}$ \\
\hline \multirow{2}{*}{ Edificações } & $\begin{array}{l}\text { Ocupação por residências, } \\
\text { comércio e indústria }\end{array}$ & $\begin{array}{l}\text { Percentual da APP ocupada com casas, lojas e } \\
\text { fábricas. }\end{array}$ \\
\hline & $\begin{array}{l}\text { Ocupação por equipamentos } \\
\text { públicos, parques e quadras }\end{array}$ & $\begin{array}{l}\text { Percentual da APP ocupada por praças, pátios e } \\
\text { quadras poliesportivas. }\end{array}$ \\
\hline
\end{tabular}

Fonte: adaptado de Freitas Filho (2010). 
A penúltima etapa foi o registro dos dados em SIG, através do software Qgis 3.10.1 para análise através de fotointerpretação. O método "on screen" foi utilizado a fim de estipular o uso e ocupação do solo baseando-se na construção de linhas, pontos e polígonos que representam feições da realidade.

Para delimitação destes usos, foi utilizado um tema baseado nos indicadores dos trabalhos de Dalla Costa (2008) e Freitas Filho (2010), expostos no Quadro 01. Muito embora os trabalhos citados procurem quantificar a degradação encontrada, esse artigo ficará limitado às análises espaciais dos parâmetros. A lógica de cada análise também se encontra resumida no Quadro 01.

A última etapa do processo metodológico refere-se à elaboração de materiais cartográficos, além da análise dos resultados e discussões - através do software QGis 3.10.1.

\section{RESULTADOS E DISCUSSÃO}

O ortomosaico obtido apresentou resolução espacial de $6 \mathrm{~cm}^{2} /$ pixel, resultado extremamente significativo, uma vez que, satélites como o Sentinel 2 e Landsat 8, por exemplo, têm em suas imagens resoluções de $20 \times 20$ e 30x30 metros, respectivamente. A Figura 3 apresenta imagens obtidas pelo levantamento aerofotogramétrico, à esquerda, e imagens oriundas do satélite Sentinel 2, à direita. Os recortes ocorreram na mesma área, mostrando a discrepância na resolução espacial. Todas as imagens estão na escala 1:175.

Figura 3. Ortomosaico apresentado pelo Sentinel 2 e pelas imagens do VANT
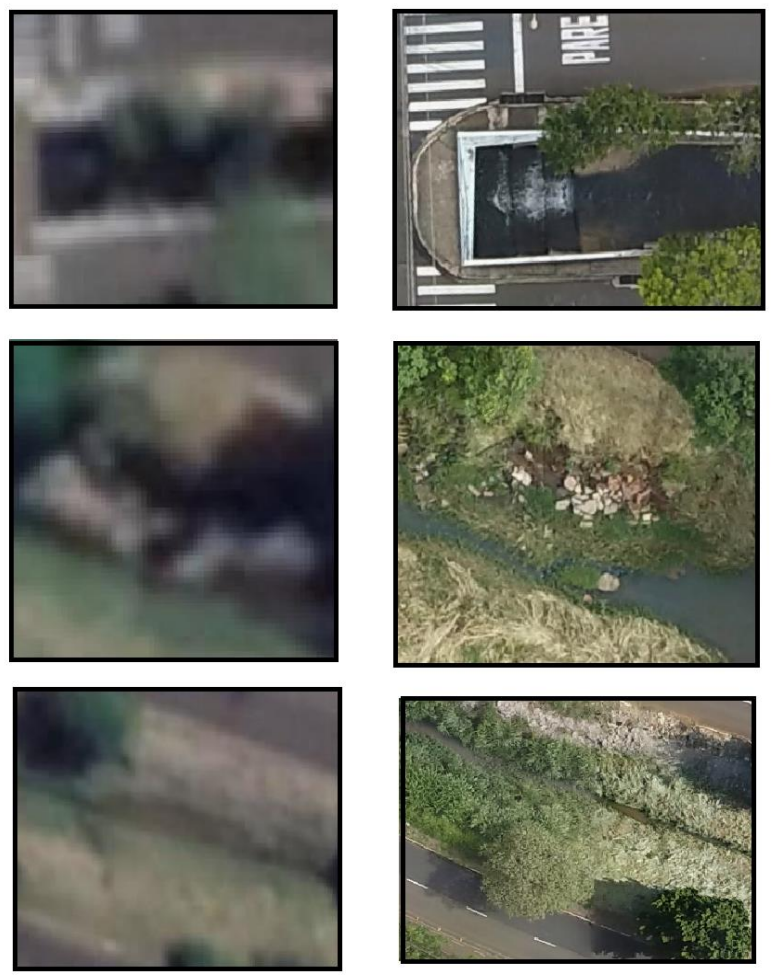

Org.: Autores (2021)

A qualidade das imagens possibilitou delimitar o uso e ocupação do solo - através da ferramenta "buffer" - responsável pela delimitação da APP, com 30 metros de margem, conforme previsto no Código Florestal 
brasileiro (BRASIL, 2012). Assim, após a fotointerpretação da imagem, foi delimitado o uso da APP desse trecho do rio urbano, conforme a Figura 4. As análises de área, englobando a demarcação da APP, de mata ciliar e de edificações, se mostraram bastante satisfatórias. A alta resolução espacial da imagem permite realizar um traçado claro entre regiões de diferentes características. Foi encontrada uma área verde de 0,064 $\mathrm{Km}^{2}$, o que representa $36,36 \%$ da área total da APP relativo ao curso d'água. Isso demonstra que há uma degradação acentuada da vegetação ripária, expondo o rio urbano a diversas outras mazelas.

Figura 4. Uso do Solo na Área de Preservação Permanente

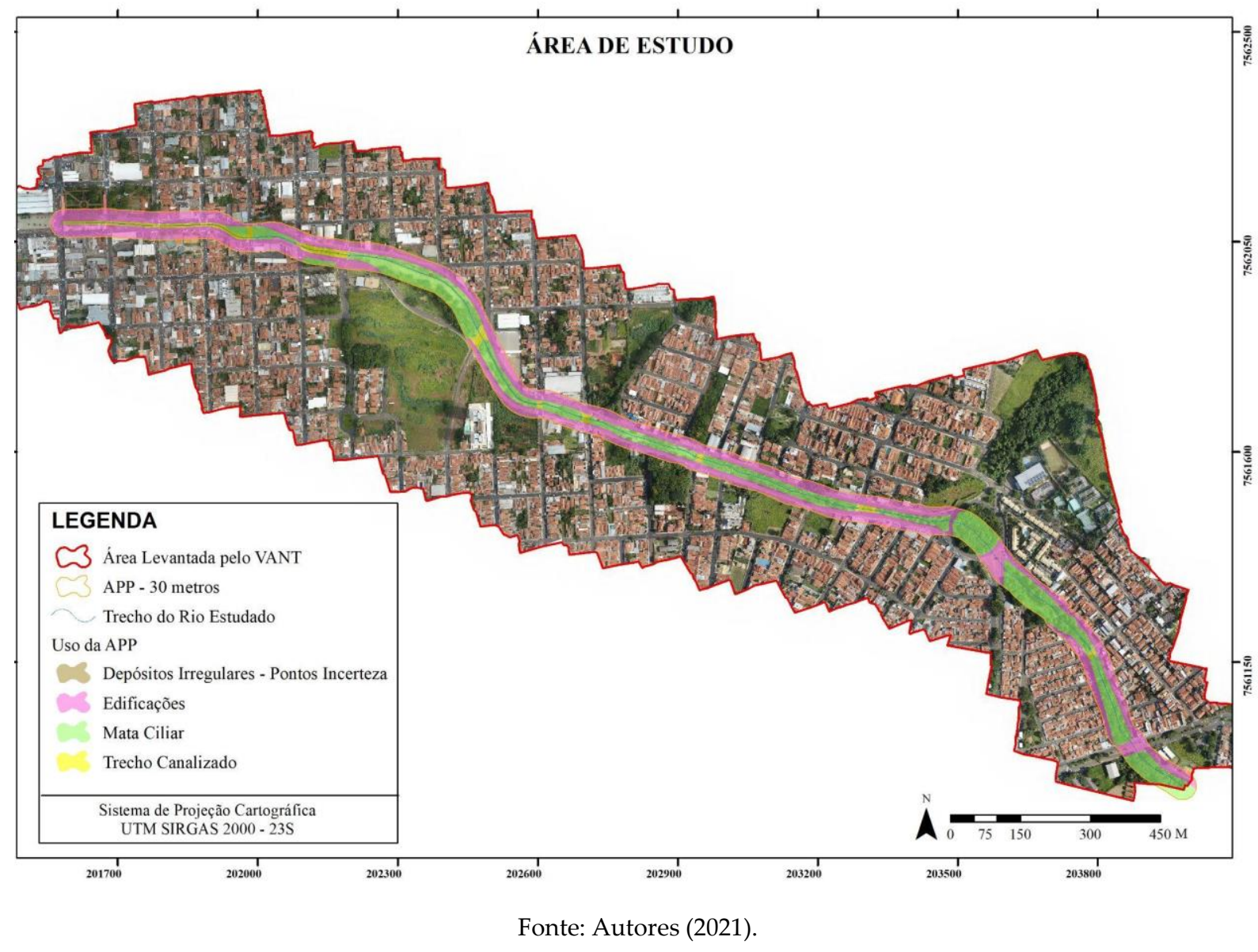

De forma complementar, foi demarcada uma área de $0,104 \mathrm{Km}^{2}$ de edificações em área protegida. Trata-se de uma substancial impermeabilização do entorno do rio, que acarreta no aumento do volume de água que chega ao mesmo, e consequentemente facilita a ocorrência de enchentes. Além do arrasto de carga poluidora das ruas pelo escoamento superficial da chuva, que leva óleos, graxa, fuligem e outros materiais para o já frágil ecossistema.

Referente às modificações nas margens e leito do rio, as imagens geradas possibilitaram a fácil verificação dos trechos que sofreram intervenções e seus comprimentos. Foi possível também identificar o tipo de revestimento adotado nessas intervenções, no caso, concreto. Tendo $28,08 \%$ do trecho modificado, fica evidenciado o grau de degradação causado no ecossistema fluvial, alterando seu comportamento hidrológico. 
No que diz respeito à análise da poluição, foi possível identificar, a partir do imageamento realizado, pontos com vestígios de resíduos de construção civil, descarte de pneus e manilhas que desaguam no curso d'água, conforme visto na figura 5.

Figura 5. Locais de incertezas quanto a depósitos irregulares

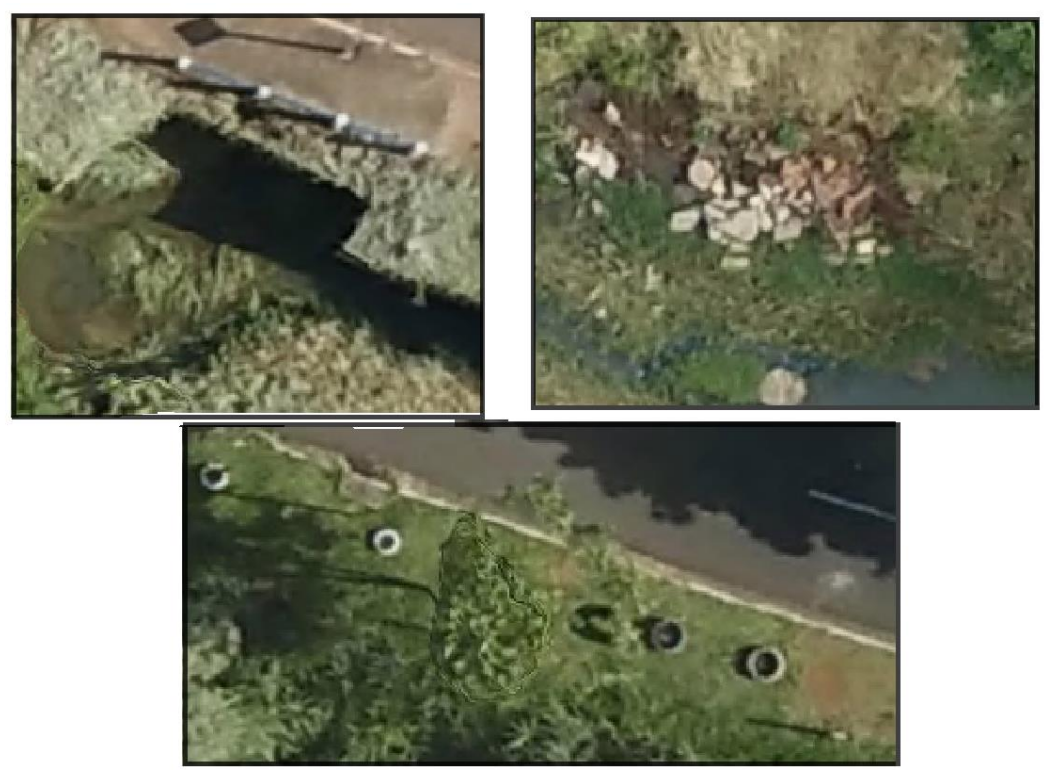

Fonte: Autores (2021).

Entretanto, tais evidências requerem visitas de campo para confirmação, uma vez que pode se tratar de manilha para drenagem pluvial, dentre outras possibilidades. Além disso, os outros materiais visualizados podem ter outras características e funções e não se tratar necessariamente de resíduo sólido, ou podem ainda já ter sido removidos, caso a imagem não seja recente. De qualquer forma, as imagens geradas pelo VANT ajudam a identificar pontos a serem visitados, agilizando o processo de análise.

De maneira similar, a identificação de pontos de erosão nas margens, ou de assoreamento no leito, podem se encontrar "camuflados" por vegetação, e se aconselha visita de campo. No trecho estudado, não foram identificados pontos de erosão.

\section{CONCLUSÕES}

A partir desse trabalho, é possível perceber que a utilização de imagens provenientes de VANT's tem total capacidade de auxiliar na identificação dos processos de degradação de ecossistemas fluviais em áreas urbanas, apresentando uma qualidade muito superior às alternativas disponíveis atualmente, como imagens livres de satélites. A resolução espacial alcançada pelas imagens permite a identificação precisa da calha do rio, e consequentemente de sua APP associada, bem como das áreas de mata ciliar, de edificações invasoras, e de outras características importantes, como canalizações, pontos de descarte de resíduos, e mudanças no revestimento das margens, auxiliando no planejamento urbano e territorial.

Conforme era esperado, o imageamento se mostrou muito eficaz para a demarcação de áreas e características lineares através de vetorização em sistemas de informação geográfica, entretanto análises mais pontuais relacionadas a locais de processo erosivo, de lançamento de efluentes ou descarte de resíduos sólidos precisam de visita complementar ao campo a fim de se verificar melhor o contexto e a real presença 
dos vestígios apontados nas imagens. Nota-se, portanto, que o imageamento caracteriza melhor estruturas consolidadas do meio urbano, enquanto características intermitentes ou discretas requerem análise complementar.

\section{REFERÊNCIAS}

BATISTA DE FRANÇA, Karla. Os gargalos para a provisão habitacional em municípios de pequeno porte: análise do programa Minha Casa, Minha Vida. Revista Brasileira de Gestão Urbana. São Paulo, SP, v. 7, n.3, p.325-339, 2017.ISSN 2175-3369. Disponível em:

https://periodicos.pucpr.br/index.php/Urbe/article/view/22055>. Acesso em: 11 de maio de 2021.

BRASIL. Código Florestal - Lei n. 12651, de 25 de maio de 2012. Dispõe sobre a proteção da vegetação nativa; altera as Leis n⿳o s 6.938, de 31 de agosto de 1981, 9.393, de 19 de dezembro de 1996, e 11.428, de 22 de dezembro de 2006; revoga as Leis n⿳⺈ ${ }^{\mathrm{o}}$ 4.771, de 15 de setembro de 1965, e 7.754, de 14 de abril de 1989, e a Medida Provisória no 2.166-67, de 24 de agosto de 2001; e dá outras providências. Diário Oficial da União. Brasília, DF, 25 jul. 2012. Disponível em: <http://www.planalto.gov.br/ccivil_03/_ato20112014/2012/lei/112651.htm>. Acesso em: 03 jun. 2021.

COSTA, Ronaldo Cataldo. Parques Fluviais na Revitalização de Rios e Córregos Urbanos. 2011. Dissertação (Mestrado em Geografia) - Instituto de Ciências Humanas e da Informação, Universidade Federal do Rio Grande, Rio Grande do Sul, 2011.

COY, Martin. A interação rio-cidade e a revitalização urbana: experiências europeias e perspectivas para a América Latina. Confins Revista Franco-Brasileira de Geografia. Paris, n.18, 2013. ISSN 1958-9212. Disponível em < https://confins.revues.org/8384?lang=pt > acesso em 18 de maio de 2021. doi:https://doi.org/10.4000/confins.8384.

CURETON, P. Digital Twins, smart cities and drones. In: CURETON, P. (org.) Drone Futures.1.ed. Londres: Routledge, 2020, p. 34.

DALLA COSTA, Simone. Estudo da viabilidade de revitalização de curso d'água em área urbana: estudo de caso no rio córrego grande em Florianópolis, Santa Catarina. 2008. Dissertação (Mestrado em Engenharia Ambiental) - Centro Tecnológico, Universidade Federal de Santa Catarina, Santa Catarina, 2008.

FREITAS FILHO, Maurício David de. Indicadores de degradação de cursos d'água em áreas urbanas. 2010. Trabalho de conclusão de curso (Graduação em Engenharia Sanitária e Ambiental) - Departamento de Engenharia Sanitária e Ambiental, Universidade Federal de Santa Catarina. Santa Catarina, 2010.

GALLACHER, David. Drone Applications for Environmental Management in Urban Spaces: A Review. International Journal of Sustainable Land Use and Urban Planning. v. 3, n.4, p. 1-14. 2016. ISSN 19278845. Disponível em: https://pdfs.semanticscholar.org/c4e7/c8805d605098b2ab66225a7c945eb2167597.pdf>. Acesso em: 15 de maio de 2021. doi:10.24102/ijslup.v3i4.738.

ROLNIK, R. Guerra dos Lugares: a colonização da terra e da moradia na era das finanças. 2.ed. São Paulo: Boitempo, 2015. p. 423. 
SEADE - Fundação Sistema Estadual de Análise de Dados. Banco de dados de informações dos municípios paulistas. Portal de Estatísticas do Estado de São Paulo. Disponível em:

$<$ http://www.perfil.seade.gov.br/>. Acesso em: 07 de maio de 2021.

VILLAÇA, F. Espaço intra-urbano no Brasil. 2.ed. São Paulo: Studio Nobel, 2001. 323 p. 